\title{
TIPPLING BUT NOT TOPPLING: EUBULUS PCG FR. 123
}

Eubulus fr. 123 Kassel-Austin = fr. 126 Hunter is incompletely preserved in the epitome of Athenaeus 1.23b.

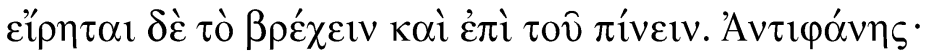

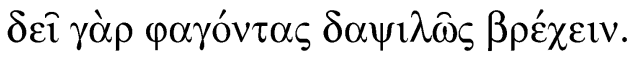

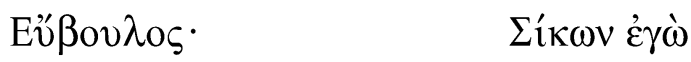

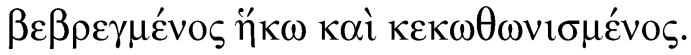

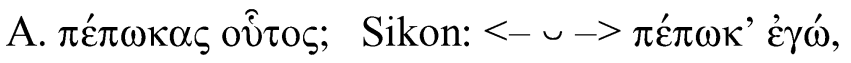

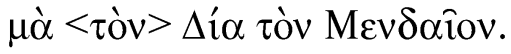

The word brechein [lit. 'moisten'] has also been said of drinking. Antiphanes:

'After all, those who have eaten must drink [brechein] greedily.'

Eubulus: 'I, Sikon,

am here - sloshed [bebregmenos] and in my cups.' ...

A: 'Hey, are you drunk?' Sikon: ‘[...] I am drunk, not by Zeus of Mende.'

The epitome of Athenaeus does not retain all the details of how these comic fragments were embedded in the conversation which Athenaeus originally presented, though the extract's first sentence shows that one purpose was to exemplify the application of $\beta \rho \varepsilon ́ \chi \omega$ to drinking. Editors of both Athenaeus and Eubulus have left the connection of his fragment to its conversational context at that. ${ }^{1}$ I submit that what follows in the epitome, as well as what precedes, may cast light both on that connection and on how we should restore the text.

My thanks to Richard Hunter and Alan Sommerstein for comments and criticisms. 
Athenaeus' epitome continues with:

(1) an initial claim that the proper application of $\dot{\alpha} v \alpha \pi i \pi \tau \omega$ is to the soul ('I flag');

(2) citations for other senses of the verb, namely 'I give ground' (Thucydides 1.70) and 'I lean back' of rowers (Cratinus $P C G$ fr. 332, Xenophon Oec. 8.8);

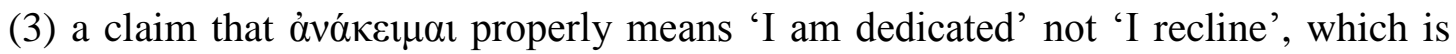
$\kappa \alpha \tau \alpha ́ \kappa \varepsilon \iota \mu \alpha \imath$ or $\kappa \alpha \tau \alpha \kappa \lambda i ́ v \omega ;$

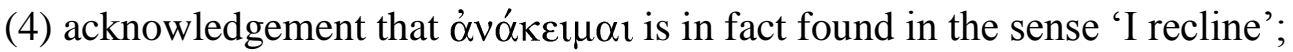

(5) an abrupt return at $23 \mathrm{e}$ to citations of $\alpha v \alpha \pi i \pi \tau \omega$, this time in the sense 'I fall on my back' (Euripides Cyc. 410, Alexis $P C G$ fr. 295).

To judge from the parts of Athenaeus where we do not rely on an epitome, Larensis' guests were competing in mastery of the polyvalence of $\alpha \dot{\alpha} \alpha \pi i \pi \tau \omega$ and, in passing, of the similar

\footnotetext{
${ }^{1}$ Besides $P C G$ vol. 5 see G. Kaibel, Athenaei Naucratitae Dipnosophistarum libri XV, vol. 1 (Leipzig, 1887); A.M. Desrousseaux and C. Astruc, Athénée de Naucratis: Les Deipnosophistes: livres I-II (Paris, 1956); R.L. Hunter, Eubulus: The Fragments (Cambridge, 1983); S.D. Olson, Athenaeus: The Learned Banqueters, vol. 1 (Cambridge, Ma., 2006). Kaibel suggested <ov̉ $\mu \varepsilon \tau \tau^{\prime} \omega \varsigma>$. J.P. Postgate, 'A few notes on Athenaeus', CQ 2 (1908),

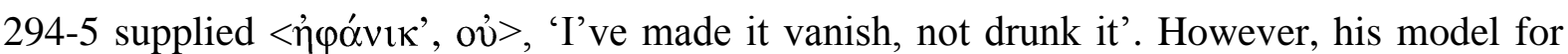
this (Plaut. MG 833-4 di me perdant si bibi... obsorbui, 'I'm damned if I drank... I glugged') works better because the punchline comes second. Desrousseaux and Astruc supplied <ov $\chi$ öбov> and assigned all of lines 3-4 to 'A.'; I do not see parallels for a peremptory question with ỡ $\tau$ o being merely rhetorical.
} 
verb $\alpha v_{\alpha} \alpha \varepsilon \varepsilon \mu \alpha .^{2}$ (4) refutes (3). (2) may similarly refute (1), or be a qualification offered by the initial speaker. (5) adds a point overlooked in (1)-(2), and was perhaps uttered by the same character as (4) and with the same critical tone.

With a very slight emendation we can restore the fragment of Eubulus so that it would naturally spark the ensuing linguistic discussion of $\dot{\alpha} v \alpha \pi i \pi \tau \omega$.

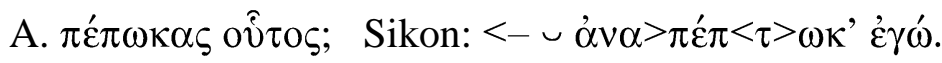

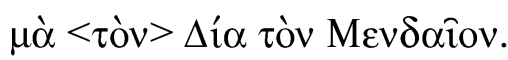

Sikon's use of (-) $\varepsilon^{\prime} \pi \tau \omega \kappa \alpha$ after $\pi \dot{\varepsilon} \pi \omega \kappa \alpha \varsigma$ would be a pun, corrupted plausibly enough through assimilation. Claim (1) would follow as an interpretation of the sense of the fragment, or in the context of claiming that Sikon (or Eubulus) misused the verb; claim (5) would circle back to correct this.

What should fill the remaining syllables? The $\mu \alpha$ s strongly suggests that Sikon's asseveration was negated, which leads me to suggest <ov่ $\left.\delta \varepsilon \gamma^{\prime}\right\rangle$. The whole fragment might then be translated:

Sikon: I, Sikon, am here - sloshed and in my cups.

A.: Hey, are you off your face?

Sikon: No, by Zeus of Mende - I am not even off my feet!

${ }^{2}$ For a particularly stimulating discussion of the dynamics of competitive citation in Athenaeus see C. Jacob, 'La citation comme performance dans les Deipnosophistes d'Athénée', in C. Darbo-Peschanski (ed.), La citation dans l'antiquité (Grenoble, 2004), 14774. 
This reconstruction fits a comic and (within the realm of drunkenness) coherent scenario, though naturally the details cannot all be reconstructed with confidence. Sikon first acknowledges that he is drunk, then denies it: this abrupt volte-face is an attempted cover-up, motivated by the intervention of the other speaker ('A.'). The likely tone of this intervention

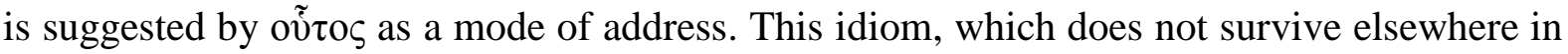
Eubulus' fragments, is particularly frequent in Aristophanes and Menander where it either grabs attention or shows exasperation, and often does both. ${ }^{3}$ For a purely attention-seeking

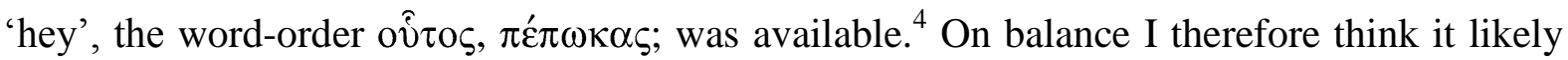
that A. is upset about Sikon's drunkenness; Sikon tends to be a cook's name, so A. could be the man who has hired him. ${ }^{5}$ Sikon would in this scenario have delivered his first utterance without anticipating A.'s presence. A. could be present onstage already, or enter immediately and see Sikon reeling, or holding up a large cup (say). Sikon's cover-up would be inebriatedly inept, since he cannot keep himself from a merry pun, whose point is that he clearly cannot be called drunk if he has not yet fallen on his back. He then chooses to swear

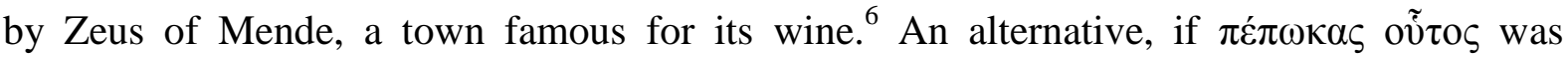
compatible with friendliness in a colloquial register free from politeness strategies, would be that A. is well-disposed to Sikon, whose silly answer is drunken banter.

\footnotetext{
${ }^{3}$ E. Dickey, Greek Forms of Address (Oxford, 1996), 154-5 argues that the implication of exasperation or rudeness was overplayed in earlier scholarship, while accepting that it is present in many of Aristophanes' uses.

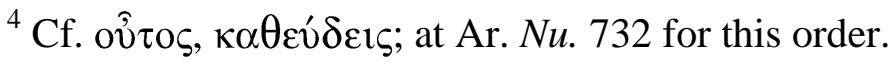

${ }^{5}$ See E.W. Handley, The Dyskolos of Menander (London, 1965) on Dysc. 889.

${ }^{6}$ This repute is discussed soon after in Ath. 1 (29d-f); see also ps.-Dem. Lacrit. 10, Men.
} $P C G$ fr. 224.5, and $\mathrm{x} 4$ in the Hippocratic Aff. Inter. 
In either scenario, if Sikon stumbles (but does not fall) after $\kappa \varepsilon \kappa \omega \theta \omega v \imath \sigma \mu \varepsilon ́ v o \zeta$, it would give further point to A.'s question and to Sikon's word-play on $\alpha \dot{v} \alpha \pi i \pi \tau \omega$. Like the statue of Anacreon described in Leonidas of Tarentum 90 G-P, wine has made his legs wobble, but he has not yet fallen.

In summary, this fragment of Eubulus stands in need of restoration. The conjecture <oủ $\delta \varepsilon^{\prime} \gamma^{\prime}$ $\dot{\alpha} \nu \alpha>\pi \varepsilon \dot{\varepsilon} \pi<\tau>\omega \kappa '$ produces a stageable snippet of dialogue and, unlike previous attempts, a good pun inside the fragment and a good logical flow in Athenaeus' epitome. 